\title{
TALENT MANAGEMENT DAN KNOWLEDGE MANAGEMENT TERHADAP KINERJA KARYAWAN DENGAN EMPLOYEE RETENTION SEBAGAI VARIABEL MODERATOR
}

\author{
Submitted Date : \\ 13 Agustus 2020 \\ Accepted Date : \\ 24 September 2020
}

Ferra Eka Ramadhani

Universitas Merdeka Malang

ferraekaramadhani@gmail.com

\author{
Harsono \\ Universitas Merdeka Malang \\ harsonohar23@gmail.com \\ Sunardi \\ Universitas Merdeka Malang \\ nardisu92@gmail.com
}

Suggested Citation:

Choirun, Ridha Nisa, Endang Siti Astuti dan Arik Prasetya, 2016, "Pengaruh Manajemen Talenta dan Manajemen

Pengetahuan terhadap Kinerja Karyawan", Jurnal Administrasi Bisnis, Vol. 39, No. 2, Page 141 - 148

\begin{abstract}
:
This study aims to describe talent management, knowledge management, employee retention and employee performance and to analyze the effect of talent management and knowledge management on employee performance through employee retention at Kanjuruhan University Malang. In this study, the population used was 98 employees and due to the relatively small number of researchers used the census method, so that all members of the population were the object of the study. The research method uses path analysis techniques. The results showed that talent management and knowledge management had a significant effect on employee retention, talent management and knowledge management had a significant effect on employee performance, employee retention had a significant effect on employee performance, talent management and knowledge management had a significant effect on employee performance through employee retention. Employee retention has not been able to mediate the effect of talent management and knowledge management on employee performance. This is because the result of the direct influence is greater than the indirect effect.
\end{abstract}

Keywords: Talent Management, Knowledge Management, Employee Retention, Employee Performance

Abstrak :

Penelitian ini bertujuan untuk mendeskripsikan talent management, knowledge management, employee retention dan kinerja karyawan serta menganalisis pengaruh talent management dan knowledge management terhadap kinerja karyawan melalui employee retention pada Universitas Kanjuruhan Malang. Populasi yang digunakan sejumlah 98 karyawan dan metode penelitian mengunakan teknik analisis path. Hasil penelitian menunjukkan bahwa talent talent management dan knowledge management berpenagruh signifikan terhadap employee retention dan kinerja karyawan, talent management dan knowledge management berpengaruh signifikan terhadap kinerja karyawan melalui employee retention. Employee retention efektif mempenagruhi talent management dan knowledge management terhadap kinerja karyawan. Hal ini diakrenakan hasil nilai pengaruh langsung lebih besar jika dibandingkan dengan pengaruh tidak langsung.

Kata Kunci : Talent Management, Knowledge Management, Employee Retention, Kinerja Karyawan

JEL Classification: 015 


\section{Pendahuluan}

Masalah sumberdaya manusia tentu tidak terlepas dari perhatian pihak manajemen atau organisasi yang melaksanakan tugas - tugasnya secara aktif dan efisien. Di dalam perusahaan sumber daya manusia sebagai penggerak serta peraih untuk keberhasilan perusahaan yang dilhat dari elemen manusianya. Perusahaan akan selalu menuntut para karyawan untuk bekerja lebih optimal lagi, guna mencapai visi dan misi perusahaan serta tujuan untuk memajukan perusahaan lebih baik. Hanya orang - orang terbaik dan mereka yang memiliki potensi yang lebih dan jumlah yang sesuai, pada posisi yang tepat dan dengan penggunaan sehiggga dapat mendorong perusahaan untuk jauh lebih meningkat.

Kemampuan setiap karyawan yang mencakup aspek pengetahuan, kemampuan dalam bersikap dan bertindak dalam bekerja serta memecahkan masalah, yang merupakan penentu tingkat produktvitas pekerjaan yang baik. Kinerja merupakan hasil kerja yang dapat dicapai pegawai baik individu maupun kelompok dalam suatu organisasi, sesuai dengan wewenang dan taggungjawab yang diberikan organisasi dalam upaya mencapai visi, misi dan tujuan organisasi bersangkutan dengan menyertakan kemampuan, ketekunan, kemandirian, kemampuan mengatasi masalah sesuai batas waktu yang diberikan secara legal, tidak melanggar hukum dan sesuai dengan moral maupun etika (Busro, 2018).

Talent management adalah mengidentifikasi, mengembangkan, mempertahankan, dan menempatkan orang tepat di tempat yang tepat. Dengan demikian "talent management berkaitan dengan mencari orang yang tepat dengan keterampilan yang tepat untuk posisi yang tepat". Semakin tingginya perhatian perusahaan terhadap talent management, maka untuk mendapatkan karyawan yang bertalenta tinggi bisa mencari dari luar maupun dari pelatihan dan kaderisasi (Busro, 2018).

Berhasilnya suatu organisasi atau perusahan tidak terlepas dari kinerja karyawan. Menerapkan adanya talent management dan knowledge management adalah merupakan usaha perusahaan dalam mempertahankan kinerja karyawan. Talent management sangat bermanfaat untuk memberikan kontribusi yang baik pada kinerja perusahaan. Meningkatkan kinerja dilihat dari talent management yaitu dengan adanya pemetaan talenta yang baik dalam penempatan posisi pekerjaan sesuai dengan kemampuan dan talenta yang dimilki oleh karyawan itu sendiri sehingga inerja mengalami peningkatan.

Selain talent management, faktor yang mendukung peningkatan kinerja yang ada di perusahaan ialah knowledge management. Knowledge management adalah perasaaan manusia utnuk melakukan proses berbagi pengetahuan, serta belajar dan bekerja bersama secara lebih efektif (Gurteen, 2016). Knowledge management sangat penting dalam pertumbuhan perusahaan terutama karyawan yang ada di divisi masing-masing, dimana dengan adanya karyawan yang memiliki knowledge management mampu dengan mudah bagi karyawan untuk berbagi informasi yang tepat dan jelas kepada para pengunjung maupun kepada sesama rekan kerja yang ada pada perusahaan.

Selain talent management dan knowledge management, faktor lain yang dapat muncul dalam upaya meningkatkan kinerja karyawan adalah employee retention. Employee retention adalah bentuk mempertahankan karyawan, yang karena beberapa alasan telah menjadi masalah utama dibanyak organisasi (Mathis dan Jackson, 2016). Sehingga dapat disimpulkan bahwa employee retention adalah mempertahankan karyawan potensial yang dimiliki perusahaan untuk tetap bertahan diperusahaan. Jika perusahaan dalam mempertahankan karyawan buruk, maka akan meningkatkan pergantian karyawan yang akan dampak terhadap pelayanan terhadap pencapaian tujuan perusahaan. Secara umum, hubungan antara mempertahankan karyawan terhadap kinerja sangatlah penting, yaitu kinerja akan buruk jika dalam mempertahakan karyawan buruk sehingga pergantian karyawan akan tinggi. Kinerja perusahaan merupakan hasil yang di pengaruhi oleh pemanfaatan sumber daya yang di miliki. Salah satu cara adalah dengan mempertahankan karyawan agar tetap memiliki loyalitas yang tinggi.

Vianny dan Susilo (2018) menunjukkan hasil penelitian manajemen talenta berpengaruh sangat kuat terhadap kinerja karyawan. Choirun, dkk (2016) menunjukkan hasil penelitian secara bersama - sama manajemen talenta dan manajemen pengetahuan berpengaruh terhadap kinerja karyawan. Harmen dan Darma (2018) semakin memperkuat pendapat diatas bahwa hasil penelitian menunjukkan secara bersama - sama dan parsial manajemen talenta dan manajemen pengetahuan berpengaruh terhadap kinerja karyawan.

Sa'diyah, dkk. (2017), Dwiki dan Yahya (2019) menunjukkan hasil penelitian bahwa retensi karyawan berpengaruh terhadap kinerja karyawan. Sedangkan penelitian Aula (2019) menunjukkan bahwa retensi karyawan mampu memediasi manajemen talenta terhadap kinerja karyawan. Sehingga retensi karyawan merupakan salah satu upaya untuk meningkatkan kinerja karyawan.

Atas dasar uraian diatas maka tujuan penelitian ini adalah untuk mengetahui pengaruh langsung talent management dan knowledge management terhadap kinerja karyawan, pengaruh langsung talent management dan 
knowledge management terhadap employee retention, pengaruh pengaruh langsung talent management dan knowledge management terhadap kinerja karyawan melalui employee retention.

\section{Metode Penelitian}

Pendekatan dalam penelitian ini adalah pendekatan kuantitatif dengan jenis penelitian explanatory research. Pada peneltian ini, populasi yang digunakan sejumlah 98 karyawan dan dikarenakan jumlah relatif kecil maka peneliti menggunakan metode sensus, sehingga semua anggota populasi dijadikan sebagai objek penelitian. Teknik pengumpulan data yang digunakan adalah kuesioner dengan menggunakan pengukuran skala likert. Teknik analisis data yang digunakan adalah analisis path.

Hasil

Hasil uji model persamaan structural sebagai berikut :

Pengujian terhadap validitas model pada analisis jalur terdapat dua indikator yaitu koefisien determinasi total $\left(R^{2}\right)$ agar dapat diketahui sahih atau tidaknya suatu analisis yang telah dilakukan. Interpretasi koefisien determinasi $\left(R^{2}\right)$ sama dengan interpretasi koefisien determinasi $\left(R^{2}\right)$ pada analisis regresi.

$$
\begin{aligned}
\mathrm{R}^{2} & =1-\mathrm{Pe}_{1}{ }^{2} \mathrm{Pe}_{2}{ }^{2} \ldots . . \mathrm{Pe}_{\mathrm{i}}{ }^{2} \\
\mathrm{P}_{\mathrm{e} 1} & =\frac{\sqrt{1-\mathrm{R}^{2}}}{1}=\sqrt{1-0,576}=0,658 \\
\mathrm{P}_{\mathrm{e} 2} & =\sqrt{1-\mathrm{R}^{2}}=\sqrt{1-0,702}=0,546 \\
\mathrm{R}^{2} & =1-(0,658)(0,546) \\
& =1-0,376 \\
& =0,641
\end{aligned}
$$

Nilai koefisien determinasi total sebesar 0,641 menunjukkan bahwa keragaman data atau informasi yang dapat dijelaskan oleh model tersebut adalah $64,1 \%$, artinya $64,1 \%$ variabel independen dapat menjelaskan kontribusinya terhadap variabel dependen. Sisanya, dijelaskan oleh variabel lain yang tidak masuk dalam model ini. Untuk mengetahui hasil analisis jalur pada penelitian ini dapat disajikan diagram path lengkap dengan koefisiennya:

\section{Gambar 1}

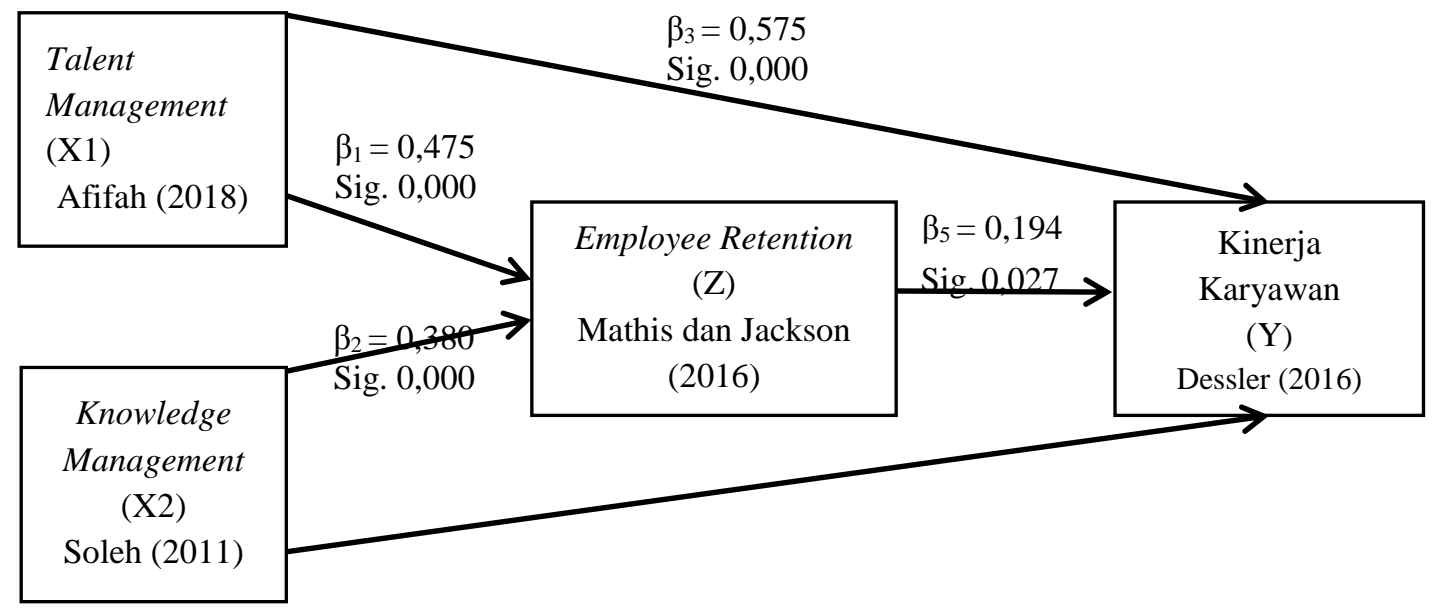

Sumber: Hasil Penelitian, 2020 (Data diolah)

Dari gambar 1 menunjukkan Talent Management (X1) dan Knowledge Management (X2) berpengaruh signifikan terhadap Kinerja Karyawan (Y) melalui Employee Retention (Z).

Pengujian hipotesis adalah sebagai berikut : 
Tabel 1. Pengaruh Langsung, Pengaruh Tidak Langsung dan Pengaruh Total

\begin{tabular}{|c|c|c|c|c|}
\hline Variabel & $\begin{array}{l}\text { Pengaruh } \\
\text { Langsung }\end{array}$ & Sig. & $\begin{array}{l}\text { Pengaruk } \\
\text { Tidak } \\
\text { Langsung }\end{array}$ & $\begin{array}{l}\text { Pengaruh } \\
\text { Total }\end{array}$ \\
\hline Talent Management terhadap Employee Retention & 0,475 & 0,000 & & \\
\hline Knowledge Management terhadap Employee Retention & 0,380 & 0,000 & & \\
\hline Talent Management terhadap Kinerja Karyawan & 0,575 & 0,000 & & \\
\hline Knowledge Management terhadap Kinerja Karyawan & 0,167 & 0,030 & & \\
\hline Employee Retention terhadap Kinerja Karyawan & 0,194 & 0,027 & & \\
\hline $\begin{array}{l}\text { Talent Management terhadap Kinerja Karyawan melalui } \\
\text { Employee Retention }\end{array}$ & & & $\begin{array}{l}0,475 \\
0,194 \\
0,092\end{array}$ & $\begin{array}{l}0,575+0,092= \\
0,667\end{array}$ \\
\hline $\begin{array}{l}\text { Knowledge Management terhadap Kinerja Karyawan melalui } \\
\text { Employee Retention }\end{array}$ & & & $\begin{array}{l}0,380 \\
0,194 \\
0,074\end{array}$ & $\begin{array}{l}0,167+0,074= \\
0,241\end{array}$ \\
\hline
\end{tabular}

Sumber: Hasil Penelitian, 2020 (Data diolah)

Tabel $1 \mathrm{di}$ atas, berdasarkan perbandingan pengaruh langsung talent management $(0,475)$, knowledge management $(0,380)$ dan pengaruh tidak langsung talent management $(0,092)$, knowledge management $(0,074)$. Kesimpulannya, pengaruh langsung menunjukkan hasil lebih besar dari penagruh tidak langsung, sehingga variabel employee retention termasuk variabel moderating.

\section{Pembahasan}

\section{Deskripsi Talent Management, Knowledge Management, Employee Retention dan Kinerja Karyawan}

Kinerja Karyawan ditentukan oleh kualitas, kuantitas, ketepatan waktu, efektivitas, kemandirian dan komitmen. Kontribusi utama pada kinerja karyawan adalah kualitas yang tercermin dari dapat menyelesaikan pekerjaan. Kinerja karyawan di Universitas Kanjuruhan Malang tergolong baik, hal ini ditunjukkan dengan kemampuan karyawan dapat menyelesaikan pekerjaan sehingga dapat memenuhi tujuan perusahaan. Hasil penelitian ini sejalan dengan pendapat Aula (2019) yang menyatakan bahwa kinerja karyawan yang baik dapat ditujukkan dengan mampu menyelesaikan pekerjaan tepat waktu.

Employee Retention ditentukan oleh komponen organisasi, peluang karir organisasi, penghargaan, rancangan tugas dan pekerjaan, hubungan karyawan. Kontribusi utama pada employee retention adalah komponen organisasi yang tercermin dari memiliki budaya dan nilai positif. Bentuk kepedulian Universitas Kanjuruhan Malang terhadap karyawan yaitu dengan memiliki nilai budaya dan nilai positif serta kompensasi yang kompetitif agar akryawan merasa nyaman dalam bekerja. Hasil penelitian ini sejalan dengan pendapat Aula (2019) menyatakan ketika diberikannya materil dalam bentuk tunjangan dan non materil dalam bentuk budaya dengan nilai yang positif sebagai usaha untuk mempertahankan karyawan agar tetap loyal pada perusahan.

Talent Management ditentukan oleh recruitment, retain dan developing. Kontribusi utama pada talent management adalah recruitment yang mengisi jabatan sesuai keahlian. Adanya informasi lowongan dari media massa memudahkan Unievrsitas Kanjuruhan Malang untuk menemukan kandidat karyawan yang bertalenta sehingga dapat mengisi jabatan sesuai keahlian. Hasil penelitian ini sejalan dengan pendapat Aula (2019) menyatakan ketika pekerjaan yang diberikan sudah sesuai dengan keahliannya, maka mereka dapat menyelesaiakan pekerjaan dengan lebih efisien.

Knowledge Management ditentukan oleh identifikasi pengetahuan, refleksi pengetahuan, berbagi pengetahuan dan penggunaan pengetahuan. Kontribusi utama pada knowledge management adalah identifikasi pengetahuan yang memiliki pengetahuan sama. Knowledge management berperan sebagai salah satu faktor dalam strategi perusahaan untuk mengembangkan karyawan. Adanya pengetahuan yang sama antar karyawan dapat memberikan inovasi inovasi baru dalam pengetahuan yang belum dimiliki sehingga karyawan memiliki pengetahuan yang luas. Hasil penelitian ini sejalan dengan pendapat Harmen dan Tri (2018) menyatakan bahwa penegtahuan yang dimiliki orgnisasi harus bisa memebrikan kemajuan bagi karyawan maupun organisasi itu sendiri.

\section{Pengaruh Talent Management terhadap Employee Retention}

Talent management berpengaruh positif dan signifikan terhadap employee retention, yang bermakna semakin tinggi talent management dapat meningkatkan employee retention. Talent management merupakan serangkaian proses untuk mengidentifikasi, mempertahankan dan menempatkan orang yang tepat ditempat yang tepat. Indikator talent management yang memberikan kontribusi terbesar terhadap peningkatan employee retention adalah recruitment 
tercermin dari mengisi jabatan sesuai keahlian dengan memberikan informasi lowongan melalui media massa. Langkah penting dari talent management adalah retensi karyawan berbakat dalam organsiasi. Karyawan merupakan investasi utama organisasi, sehingga karaywan berbakat perlu dipertahankan dalam organisasi. Usaha dalam mempertahankan karyawan yang berbakat sudah dilakukan yaitu dengan memiliki budaya dan nilai positif dan kompensasi yang kompetitif. Selain itu karyawan diberikan jabatan sesuai dengan keahliannya sehingga karyawan akan merasa antusiasme dalam bekerja ketika perusahaan bisa memebrikan jabatan sesuai dengan bidang kemampuan mereka. Talent management merupakan proses penyaluran bakat dalam pengelolaan Sumber Daya Manusia, penyaluran bakat karaywan mendorong employee retention agar organisasi mampu memiliki daya saing dalam lingkungan kompetitif. Hal ini sejalan dengan penelitian yang dilakukan oleh Putri dan Subudi (2018) menyatakan bahwa talent management berpengaruh langsung terhadap employee retention.

\section{Pengaruh Knowledge Management terhadap Employee Retention}

Knowledge management berpengaruh positif dan signifikan terhadap employee retention, yang bermakna semakin tinggi knowledge management dapat meningkatkan employee retention. Knowledge management merupakan upaya penciptaan, penimpanan, penyebaran dan penerapan pengetahuan untuk meningkatkan kinerja. Indikator knowledge management yang memberikan kontribusi terbesar terhadap peningkatan kinerja karyawan adalah identifikasi pengetahuan tercermin dari memiliki pengetahuan sama dengan melakuakn inovasi baru. Knowledge management menjadi hal penting dalam proses pembelajaran sebuah organisasi, pengetahuan yang dimiliki organisasi harus mampu memberikan kemajuan bagi karyawan. Sehingga kemampuan dalam mengelola pengetahuan dapat mendorong organisasi untuk lebih kompetitif. Karyawan yang memiliki talenta harus didukung dengan pengetahuan agar terus berkembangan dan dapat meningkatkan kinerja karyawan secara signfikan. Hal ini sejalan dengan penelitian yang dilakukan oleh Surbakti dan Ta'a (2016) menyatakan bahwa knowledge management berpengaruh signifikan terhadap employee retention.

\section{Pengaruh Talent Management terhadap Kinerja Karyawan}

Talent management berpengaruh positif dan signifikan terhadap kinerja karyawan, yang bermakna semakin tinggi talent management dapat meningkatkan kinerja karyawan. Talent management merupakan serangkaian proses untuk mengidentifikasi, mempertahankan dan menempatkan orang yang tepat ditempat yang tepat. Indikator talent management yang memberikan kontribusi terbesar terhadap peningkatan kinerja karyawan adalah recruitment tercermin dari mengisi jabatan sesuai keahlian dengan memberikan informasi lowongan melalui media massa. Dengan adanya informasi lowongan melalui media massa maka akan dapat memperoleh kandidat yang memiliki talent untuk mengisi jabatan sesuai keahlian. Ketika sudah memperoleh kandidat yang bertalenta maka akan dilakukan orientasi, pelatihan yang sesuai dengan keahlian untuk mendukung ketrampilan karyawan agar siap bekerja. Ketika talenta yang dimiliki karyawan dapat dikelola dengan baik oleh organisasi maka setiap karyawan mampu menghasilkan kinerja yang optimal, sehingga dapat meningkatkan kinerja organisasi. Hal ini sejalan dengan penelitian yang dilakukan oleh Harmen dan Tri (2018), Aula (2019) menyatakan bahwa talent management berpengaruh signifikan terhadap kinerja karyawan. Diperkuat dengan temuan dari penelitian yang dilakukan oleh Kardo, dkk (2020) dan Tri, dkk (2020) menyatakan bahwa talent management berpengaruh signifikan terhadap kinerja karyawan.

\section{Pengaruh Knowledge Management terhadap Kinerja Karyawan}

Knowledge management berpengaruh positif dan signifikan terhadap kinerja karyawan, yang bermakna semakin tinggi knowledge management dapat meningkatkan kinerja karyawan. Knowledge management merupakan upaya penciptaan, penimpanan, penyebaran dan penerapan pengetahuan untuk meningkatkan kinerja. Indikator knowledge management yang memberikan kontribusi terbesar terhadap peningkatan kinerja karyawan adalah identifikasi pengetahuan tercermin dari memiliki pengetahuan sama dengan melakuakn inovasi baru. Knowledge management menjadi hal penting dalam proses pembelajaran sebuah organisasi, pengetahuan yang dimiliki organisasi harus mampu memberikan kemajuan bagi karyawan. Sehingga kemampuan dalam mengelola pengetahuan dapat mendorong organisasi untuk lebih kompetitif. Karyawan yang memiliki talenta harus didukung dengan pengetahuan agar terus berkembangan dan dapat meningkatkan kinerja karyawan secara signfikan. Hal ini sejalan dengan penelitian yang dilakukan oleh Choirun, et al (2016) dan Harmen dan Tri (2018) menyatakan bahwa manajemen 
pengetahuan berpengaruh signifikan terhadap kinerja karyawan. Diperkuat dengan temuan dari penelitian yang dilakukan oleh Jamaludin (2019) dan Kardo, dkk (2020) menyatakan bahwa knowledge management berpengaruh signifikan terhadap kinerja karyawan.

\section{Pengaruh Employee Retention terhadap Kinerja Karyawan}

Employee retention berpengaruh terhadap kinerja karyawan, yang bermakna semakin tinggi employee retention dapat meningkatkan kinerja karyawan. Employee retention merupakan kemampuan perusahaan untuk mempertahankan karyawan potensial yang dimiliki perusahaan. Indikator employee retention yang memberikan kontribusi terbesar terhadap peningkatan kinerja karyawan adalah komponen organisasi yang tercermin dari memiliki budaya dan nilai positif dengan memberikan kompensasi yang kompetitif. Adanya budaya yang memiliki nilai positif dan adanya kompensasi yang kompetitif membuat karyawan merasa nyaman dan semangat dalam bekerja. Ketika harapan karyawan dapat dipenuhi oleh organisasi akan dapat mendorong karyawan utnuk semangat dalam bekerja. Hal ini akan menimbulkan rasa sukarela karyawan untuk mendedikasikan dirinya untuk organisasi sehingga dapat meningkatkan kinerja karyawan. Sejalan dengan penelitian yang dilakukan oleh Sa'diah, et al (2017) menyatakan bahwa employee retention berpengaruh langsung terhadap kinerja karyawan. Diperkuat dengan temuan dari penelitian yang dilakukan oleh Dwiki dan Yahya (2018) menyatakan bahwa retensi karyawan berpengaruh signifikan terhadap kinerja karyawan.

\section{Pengaruh Talent Management dan Knowledge Management terhadap Kinerja Karyawan melalui Employee Retention}

Employee retention memediasi pengaruh talent management terhadap kinerja karyawan, yang berarti bahwa talent management dapat meningkatkan kinerja karyawan jika karyawan merasa puas dengan kompensasi yang diberikan sehingga karyawan memiliki loyalitas terhadap perusahaan. Employee retention merupakan strategi penting dalam mencapai tujuan organisasi yaitu mempertahankan karyawan yang berbakat. Karyawan merupakan investasi utama organisasi, sehingga karyawan berbakat perlu dipertahankan dalam organisasi. Usaha dalam mempertahankan karyawan yang berbakat sudah dilakukan yaitu dengan memiliki budaya dan nilai positif dan kompensasi yang kompetitif. Selain itu karyawan diberikan jabatan sesuai dengan keahliannya sehingga karyawan akan merasa antusiasme dalam bekerja ketika perusahaan bisa memberikan jabatan sesuai dengan bidang kemampuan mereka. Sejalan dengan penelitian yang dilakukan oleh Aula (2019) menyatakan bahwa manajemen talenta berpengaruh signifikan terhadap kinerja karyawan melalui retensi karyawan.

Employee retention memediasi pengaruh knowledge management terhadap kinerja karyawan, yang berarti bahwa knowledge management dapat meningkatkan kinerja karyawan jika karyawan memiliki inovasi baru yang bermanfaat untuk organsiasi maka hal ini akan menajdi pertimbangan organisasi utnuk mempertahankan karyawan tersebut. Employee retention merupakan strategi penting dalam mencapai tujuan organisasi yaitu mempertahankan karyawan yang berbakat. Knowledge management menjadi hal penting dalam proses pembelajaran sebuah organisasi, pengetahuan yang dimiliki organisasi harus mampu memberikan kemajuan bagi karyawan. Sehingga kemampuan dalam mengelola pengetahuan dapat mendorong organisasi untuk lebih kompetitif. Karyawan yang memiliki talenta harus didukung dengan pengetahuan agar terus berkembangan dan dapat meningkatkan kinerja karyawan secara signfikan.

\section{Kesimpulan}

Ternyata Talent management dan knowledge management berpengaruh terhadap employee retention, yang berarti bahwa semakin tinggi talent management yang mengisi jabatan sesuai keahlian, didukung knowledge management yang melakukan inovasi baru sehingga dapat meningkatkan employee retention. Talent management dan knowledge management berpengaruh terhadap kinerja karyawan. Hal ini berarti bahwa kinerja karyawan dapat ditingkatkan melalui talent management dengan mengisi jabatan sesuai keahlian, didukung knowledge management dengan melakukan inovasi baru. Employee retention berpengaruh terhadap kinerja karyawan, yang berarti bahwa employee retention yang memiliki budaya dan nilai positif dapat meningkatkan kinerja karyawan. Employee retention memediasi pengaruh talent management dan knowledge management terhadap kinerja karyawan. Hal ini bermakna bahwa kinerja karyawan dapat ditingkatkan jika karyawan memiliki talent management dan knowledge management yang didukung oleh employee retention. Saran bagi peneliti selanjutnya yaitu dapat melakukan pengambilan data dalam waktu yang sama. Dengan adanya temuan ini diharapkan dapat memberikan kontribusi pengembangan ilmu manajemen pada Manajemen Sumber Daya Manusia. 
Daftar Pustaka

Aula Rahmawati, Hanum. (2019). Pengaruh Manajemen Talenta Terhadap Kinerja Karyawan Melalui Retensi Pada Bpr Bank Daerah Lamongan, Jurnal IImu Manajemen (Jim), 7 (2)

Busro, Muhammad. (2018). Teori - Teori Manajemen Sumber Daya Manusia, Jakarta : Prenadamedia Group

Choirun Nisa, Ridha, Endang Siti Astuti Dan Arik Prasetya. (2016) "Pengaruh Manajemen Talenta Dan Manajemen Pengetahuan Terhadap Kinerja Karyawan", Jurnal Administrasi Bisnis (Jab), 39 (2)

Dwiki Putri, Intan Dan M Yahya Arwiyah. (2019). "Pengaruh Retensi Karyawan Terhadap Kinerja Karyawan Pada Pt. Kaltacitra Utama Jakarta Timur", E-Proceeding Of Management, 6 (2)

Harmen, Hilma Dan Muhammad Tri Darma. (2018). "Pengaruh Talent Management Dan Knowledge Management Terhadap Kinerja Karyawan Pt. Perkebunan Nusantara li", Jurnal Konsep Bisnis Dan Manajemen (Jkbm), 4 (2)

Jamaludin, Yovinianus. (2019). "Pengaruh Talent Management Dan Manajemen Pengetahuan Terhadap Kepuasan Kerja Dan Dampaknya Pada Kinerja Pegawai Negeri Sipil (Pns) Di Kabupaten Sanggau". Equator Journal Of Management And Entrepreneurship (Ejve), 7 (3)

Kardo, Sri Wilujeng Dan Dianawati Suryaningtyas. (2020). "Penagruh Manajemen Talenta Dan Manajemen Pengetahuan Terhadap Kinerja Karyawan Di Transformer Center Kabupaten Batu". Jurnal Riset Mahasiswa Manajemen (Jrmm), 6 (1)

Mathis, R.L \& J.H. Jackson. (2016). Human Resource Management: Manajemen Sumber Daya Manusia, Jakarta: Salemba Empat

Putri Dewi Ratnawati, Dian Dan Made Subudi. (2018). "Pengaruh Talent Management Tehadap Employee Retention Dengan Employee Engagement Sebagai Variabel Mediasi", E-Jurnal Manajemen Ubud, 7 (11)

Sa'diyah, Halimatus, S. Anugrahini Irawati Dan Faidal. (2017). "Pengaruh Employee Retention Dan Turnover Intention Terhadpa Kinerja Karyawan Melalui Kepuasan Kerja Pada Kospin Jasa Cabang Jawa Timur", Jurnal Manajemen Universitas Trunojoyo Madura

Surbakti, Herison Dan Azman Ta'a. (2016). "Improving Employees Retention Rate Through Knowledge Management And Business Intelligence Components", Knowledge Management International Conference (Kmice)

Tri Saputra, Redy, Sri Langgeng Ratnasari Dan Rona Tanjung. (2020). "Pengaruh Manajemen Talenta, Perencanaan Sdm Dan Audit Sdm Terhadap Kinerja Karyawan. Jurnal Trias Politika. 4 (1)

Vianny Oktavia, Hanna Dan Heru Susilo. (2018). "Pengaruh Manajemen Talenta Terhadap Kinerja Karyawan”, Jurnal Administrasi Bisnis (Jab), 60 (2) 